\title{
ON ONE MATHEMATICAL MODEL OF THE EXTRACTION PROCESS OF POLYDISPERSE POROUS MATERIAL
}

\author{
N.E. Erzhanov, Institute of Mathematics and Mathematical Modelling, Almaty, \\ Kazakhstan, imanbaevnur@mail.ru, \\ I. Orazov, Institute of Mathematics and Mathematical Modelling, Almaty, Kazakhstan, \\ i_orazov@mail.ru
}

\begin{abstract}
We consider a mathematical model which represents the extraction process of a target component from the polydispersed porous material. The suggested model is demonstrated by the example of a flat solid material with bidispersed pores of different size in the form of a system of channels of macropores with micropores facing their walls. The macropores and the micropores in the material have homogeneous size. We model a case when micropores of the solid material (dispersed medium) are initially filled with an oil (dispersion phase), which is our target component. The macropores are filled in with a pure solvent. In the process of extraction the oil diffuses from the micropore to the macropore, and then from the micropores to the external solvent volume, wherein the ratio of concentrations in the macropore and the micropore is taken in accordance with the linear law of adsorption. The well-posedness of the formulated mathematical model has been justified.

Keywords: processes of the extraction; polydisperse porous materials; target component; density of sources; inverse problem; diffusion equation.
\end{abstract}

\section{Introduction}

The processes of extraction from the solid polydisperse porous materials are widely distributed in the food, chemical, pharmaceutical and medical industries. Herewith the increased requirements are presented to the quality of the extract.

Occurring during the extraction the mass transfer processes, in general, are nonlinear and must be described by the appropriate mechanical-mathematical apparatus. However, considering the porosity of the structure of the particles of solid polydisperse porous materials we can greatly simplify the mathematical model of the extraction process. Thus, the surface area of contact of the phases between the particles of solid polydisperse porous materials and extractant depending on the grinding of raw materials will be greater, the smaller the size of the particles is. But the excessive grinding leads to the increasing of their total surface as well as the increasing of the likelihood of their aggregation.

At the same time, now the hydrodynamic methods of intensification (vortex extraction, mode of the vacuum boiling of the extractant, mechanical vibration of suspension, imposition of ultrasound on the suspension, pressure pulsation, spinning porous material), the effects of which can not be explained only by the theses of the diffusion theory, are widely spread.

The results of theoretical and experimental studies have shown that for many types of solid polydisperse porous materials (such as hawthorn, licorice, flowers Helichrysum, 
grass hypericum, valerian, anise seeds, fennel and others) the application of the model of diffusion-convection mechanism of the extraction leads to the fairly accurate results.

Thus, for the construction of new technologies of extraction from the solid polydisperse porous materials it is necessary to solve the problem of recovering of the parameters characterizing the properties of a material or process required to obtain the final state in a finite amount of time. Such mathematical problems are called the inverse problems of the theory of boundary value problems for partial differential equations.

The problems that imply the determination of coefficients or the right-hand side of a differential equation (together with its solution) are commonly referred to as inverse problems of mathematical physics. In this paper we consider one family of problems implying the determination of the temperature and density of heat sources from given values of the initial and final temperature. The mathematical statement of such problems leads to the inverse problem for the heat equation, where it is required to find not only a solution of the problem, but also its right-hand side that depends only on a spatial variable.

The solvability of various inverse problems for parabolic equations was studied in papers of Yu.E. Anikonov and Yu.Ya. Belov, B.A. Bubnov, A.I. Prilepko and A.B. Kostin, V.N. Monakhov, A.I. Kozhanov, K.B. Sabitov and many others. We note [1-11] from recent papers close to the theme of our article.

Unlike the preceding works, we study the inverse problem for a heat equation subject to boundary conditions with respect to a spatial variable under which the system of eigenfunctions of the corresponding spectral problem for an ordinary differential operator does not form a basis.

The papers $[12,13]$ are most close to the subject of this one. However the distinctive feature of the present paper is that an unknown right-hand side is simultaneously present both in the equation and in conditions of the initial and final redefinition in the researched inverse problems.

In papers [14-16] S.G. Pyatkov considered some mathematical models arising in filtration theory, well-posedness questions of inverse problems for mathematical models and convection-diffusion processes of heat and mass transfer.

\section{Reduction to a Mathematical Problem}

For simplicity we consider only a model equation of one-dimensional extraction process of a target component from the solid polydisperse porous materials in one separately taken macropore:

$$
\Psi_{t}(x, t)-\Psi_{x x}(x, t)=f(x)
$$

where $\Psi(x, t)$ is a dimensionless concentration of the target component in macropores at $x$ at time point $t$. Here $f(x)$ is an influence of outer source. This influence is generated by the dimensionless concentration of the target component in macropores. The influence depends only on distance to boundary of the macropore, that is only on position of the point $x$ in a liquid phase, and does not depend on time $t$.

The length of the macropore is taken equal to one in dimensionless parameters. Therefore the problem is considered in the domain $\Omega=\{(x, t): 0<x<1,0<t<T\}$. Here $t=0$ is an initial time point and $t=T$ is a final one. 
It is natural to assume that the value of concentration on the farthest boundary of the macropore equals to zero:

$$
\Psi(1, t)=0,0 \leq t \leq T .
$$

For many forms of solid polydisperse porous materials, the volume of diffusion (of the target component from micropore into macropore) at the near end at every time point $t$ is proportional to the change speed of the average value of quantity of the target component in the macropores. Then

$$
\alpha \Psi(0, t)=\frac{d}{d t} \int_{0}^{1} \Psi(\xi, t) d \xi, 0 \leq t \leq T
$$

where the proportional coefficient $\alpha$ is a positive constant.

Our goal is to find functions of influence of the outer source $f(x)$ by means of some additional information. The knowledge of $f(x)$ allows in future to calculate the necessary concentration of the target component in the micropores.

As the additional information we take values of initial and final conditions of the concentration of the target component in the macropores:

$$
\Psi(x, 0)=\varphi(x), \Psi(x, T)=\psi(x), 0 \leq x \leq 1 .
$$

Thus the investigated process is reduced to the mathematical problem: Find the righthand side $f(x)$ of the diffusion equation (1), and its solution $\Psi(x, t)$ subject to the boundary (2), (3) and the initial and final conditions (4).

The boundary condition (3) is significantly nonlocal. The integral along inner lines of the domain is present in this condition. Using the idea of A.A. Samarskii, we transform this condition. Taking into account equation (1) from (3), we get

$$
\alpha \Psi(0, t)=\int_{0}^{1}\left(\Psi_{\xi \xi}(\xi, t)+f(\xi)\right)(\xi, t) d \xi, 0 \leq t \leq T .
$$

Hence

$$
\alpha \Psi(0, t)=\int_{0}^{1} f(\xi) d \xi+\left[\Psi_{x}(1, t)-\Psi_{x}(0, t)\right], 0 \leq t \leq T .
$$

Introduce the notations

$$
u(x, t)=\Psi(x, t)+\frac{x-1}{\alpha} \int_{0}^{1} f(\xi) d \xi .
$$

Then in terms of a new function $u(x, t)$, we get the following inverse problem:

In the domain $\Omega=\{(x, t): 0<x<1,0<t<T\}$ find the right-hand side $f(x)$ of the diffusion equation

$$
u_{t}(x, t)-u_{x x}(x, t)=f(x)
$$

and its solution $u(x, t)$ that satisfies the boundary

$$
u(1, t)=0, u_{x}(0, t)-u_{x}(1, t)+\alpha u(0, t)=0,0 \leq t \leq T,
$$

and the initial and final conditions $(0 \leq x \leq 1)$ :

$$
u(x, 0)=\varphi(x)+\frac{x-1}{\alpha} \int_{0}^{1} f(\xi) d \xi, u(x, T)=\psi(x)+\frac{x-1}{\alpha} \int_{0}^{1} f(\xi) d \xi .
$$


Thus the main inverse problem (1) - (4) with the integral condition (4) is reduced to the nonlocal boundary value problem (6) - (8). This problem (6) - (8) has two specificities:

- firstly, the boundary conditions (7) are regular but not strengthened regular. It leads to the fact that the system of eigenfunctions (and associated functions) of corresponding spectral problem for an ordinary differential operator, arising in the method of variables separation, can not form even a unconditional basis in $L_{2}(0,1)$. This fact can make impossible to use the Fourier method of variables separation.

- secondly, unknown function $f(x)$ is included both in the right-hand side of equation (6) and in the conditions of initial and final redefinitions (8). This fact complicates the problem relatively earlier investigated variants.

The present paper is devoted to the overcoming of the mentioned specificities. Therefore, in the future, we consider the problem with general boundary conditions on the space variable.

\section{Inverse Problems with General Boundary Conditions on the Spatial Variable}

In contrast to the previous articles, we study inverse problems for the heat equation with general boundary conditions on the spatial variable which are regular but not strongly regular under which the system of eigenfunctions of the corresponding spectral problem for an ordinary differential operator does not form a basis.

In the domain $\Omega=\{(x, t), 0<x<1,0<t<T\}$ we consider the following problem:

Find the right-hand side $f(x)$ of the diffusion equation

$$
u_{t}(x, t)-u_{x x}(x, t)=f(x),
$$

and its solution $u(x, t)$ thar satisfies the initial and final

$$
u(x, 0)=\varphi(x), u(x, T)=\psi(x), 0 \leq x \leq 1
$$

and the boundary conditions

$$
\left\{\begin{array}{l}
a_{1} u_{x}(0, t)+b_{1} u_{x}(1, t)+a_{0} u(0, t)+b_{0} u(1, t)=0 \\
c_{1} u_{x}(0, t)+d_{1} u_{x}(1, t)+c_{0} u(0, t)+d_{0} u(1, t)=0
\end{array}\right.
$$

The parameters $a_{k}, b_{k}, c_{k}, d_{k}, k=0,1$ are arbitrary numbers, while $\varphi(x)$ and $\psi(x)$ are given functions.

The use of the Fourier method for solving of problem (9) - (11) leads to the spectral problem for the operator $l$ given by the differential expression

$$
l(y)=-y^{\prime \prime}(x), 0<x<1
$$

and general boundary conditions

$$
\left\{\begin{array}{l}
a_{1} y^{\prime}(0)+b_{1} y^{\prime}(1)+a_{0} y(0)+b_{0} y(1)=0 \\
c_{1} y^{\prime}(0)+d_{1} y^{\prime}(1)+c_{0} y(0)+d_{0} y(1)=0 .
\end{array}\right.
$$

It is known that general boundary conditions can be divided into three classes:

- strengthened regular conditions; 
- regular but not strengthened regular conditions;

- irregular conditions.

The general boundary conditions (12) are called regular if one of the following three conditions:

$$
\begin{array}{ll}
\text { i. } & a_{1} d_{1}-b_{1} c_{1} \neq 0 ; \\
\text { ii. } & a_{1} d_{1}-b_{1} c_{1}=0,\left|a_{1}\right|+\left|b_{1}\right|>0, a_{1} d_{0}+b_{1} c_{0} \neq 0 \\
\text { iii. } & a_{1}=b_{1}=c_{1}=d_{1}=0, a_{0} d_{0}-b_{0} c_{0} \neq 0
\end{array}
$$

is satisfied.

Regular boundary conditions are strengthened regular in the first and the third cases, while in the second case the additional condition

$$
a_{1} c_{0}+b_{1} d_{0} \neq \pm\left[a_{1} d_{0}+b_{1} c_{0}\right]
$$

is required.

If boundary conditions are strengthened regular then the system of root functions forms a Riesz basis in $L_{2}(a, b)$ [17-19].

\section{A Case of Sturm-Type Boundary Conditions}

A particular case of strongly regular boundary conditions is Sturm-type conditions: $b_{0}=b_{1}=c_{0}=c_{1}=0$ :

$$
\left\{\begin{array}{l}
a_{1} u_{x}(0, t)+a_{0} u(0, t)=0 \\
d_{1} u_{x}(1, t)+d_{0} u(1, t)=0 .
\end{array}\right.
$$

It is known that the eigenvalues of these problems are real and simple, and the system of their eigenfunctions constitutes an orthonormal basis for the $L_{2}(0,1)$ space.

Denote by $\lambda_{k}$ the eigenvalues of the operator $l$ enumerated in the increasing order of their absolute values, and denote by $y_{k}(x), k=1,2, \ldots$ the associated normalized eigenfunctions.

Thus, we can represent the solution $u(x, t), f(x)$ of $(9)-(11)$ as the series:

$$
u(x, t)=\sum_{k=1}^{\infty} u_{k}(t) y_{k}(x), \quad f(x)=\sum_{k=1}^{\infty} f_{k} y_{k}(x) .
$$

Inserting (13) into (9) and (10), we obtain the problems

$$
u_{k}^{\prime}(t)+\lambda_{k} u_{k}(t)=f_{k}, u_{k}(0)=\varphi_{k}, u_{k}(T)=\psi_{k},
$$

for finding of the unknown functions $u_{k}(t)$ and coefficients $f_{k}$; where $\varphi_{k}, \psi_{k}$ are the Fourier coefficients of $\varphi(x)$ and $\psi(x)$ with respect to the system $\left\{y_{k}(x)\right\}: \varphi_{k}=\left(\varphi(x), y_{k}(x)\right), \psi_{k}=$ $\left(\psi(x), y_{k}(x)\right)$.

A solution of problem (14) exists, is unique and can be written explicitly as

$$
\begin{gathered}
u_{k}(t)=e^{-\lambda_{k} t} \varphi_{k}+\frac{1-e^{-\lambda_{k} t}}{1-e^{-\lambda_{k} T}}\left(\psi_{k}-e^{-\lambda_{k} T} \varphi_{k}\right), \\
f_{k}=\frac{\lambda_{k}}{1-e^{-\lambda_{k} T}}\left(\psi_{k}-e^{-\lambda_{k} T} \varphi_{k}\right) .
\end{gathered}
$$


We should note that (15) and (16) remain valid in the case $\lambda_{0}=0$. Then, passing to the limit as $\lambda_{0} \rightarrow 0$, from (15) and (16), we obtain $u_{0}(t)=\varphi_{0}+\frac{\psi_{0}-\varphi_{0}}{T} t$ and $f_{0}=\frac{\psi_{0}-\varphi_{0}}{T}$. Thus, we will not treat this particular case separately.

Substituting (15) and (16) into (13), we arrive at a formal solution of the problem. In order to complete our study, it is necessary, as in the Fourier method, to justify the smoothness of the resulting formal solutions and the convergence of all appearing series.

Let us state the main result of this section.

Theorem 1. Suppose that $b_{0}=b_{1}=c_{0}=c_{1}=0$, i.e., that the boundary conditions (12) are Sturm-type conditions. If $\varphi(x), \psi(x) \in W_{2}^{2}(0,1)$ and the functions $\varphi(x), \psi(x)$ satisfy the boundary conditions (12), then there exists a unique generalized solution $u(x, t) \in W_{2}^{2,1}(\Omega)$, $f(x) \in L_{2}(0,1)$ of problem (9) - (11).

Proof. Considering that $\lim _{k \rightarrow \infty} \lambda_{k}=+\infty$, using (15) and (16) it is not difficult to obtain the estimates

$$
\left|u_{k}(t)\right| \leq C\left(\left|\varphi_{k}\right|+\left|\psi_{k}\right|\right), \quad\left|u_{k}^{\prime}(t)\right| \leq C\left(\left|\varphi_{k}\right|+\left|\psi_{k}\right|\right)\left|\lambda_{k}\right|, \quad\left|f_{k}\right| \leq C\left(\left|\varphi_{k}\right|+\left|\psi_{k}\right|\right)\left|\lambda_{k}\right|,
$$

which are uniform in $k$.

Hence, the uniform and absolute convergence of series

$$
\varphi^{\prime \prime}(x)=-\sum_{k=1}^{\infty} \lambda_{k} \varphi_{k} y_{k}(x), \quad \psi^{\prime \prime}(x)=-\sum_{k=1}^{\infty} \lambda_{k} \psi_{k} y_{k}(x)
$$

implies that (15) converges and the solution of $(9)-(11)$ is of the following class: $u(x, t) \in$ $W_{2}^{2,1}(\Omega), f(x) \in L_{2}(0,1)$.

Since the system $\left\{y_{k}(x)\right\}$ constitutes an orthonormal basis for $L_{2}(0,1)$, we can express every solution of (9) - (11) in this class as a series (15). The uniqueness of the construction of solutions (15) and (16) of (14) implies the uniqueness of solutions of (9) - (11). The proof of the theorem is complete.

\section{Regular but not Strengthened Regular Boundary Conditions}

In [11] we described a class of regular but not strongly regular boundary conditions in a convenient form.

Theorem 2. [11] If the boundary conditions (12) are regular but not strongly regular then the boundary conditions (11) are reduced to

$$
\left\{\begin{array}{rl}
a_{1} u_{x}(0, t)+b_{1} u_{x}(1, t)+a_{0} u(0, t)+b_{0} u(1, t)=0, \\
c_{0} u(0, t)+d_{0} u(1, t)=0,
\end{array}\left|a_{1}\right|+\left|b_{1}\right|>0\right.
$$

of one of the following four types:

$$
\begin{array}{lll}
I . & a_{1}+b_{1}=0, & c_{0}-d_{0} \neq 0 \\
\text { II. } & a_{1}-b_{1}=0, & c_{0}+d_{0} \neq 0 \\
\text { III. } & c_{0}-d_{0}=0, & a_{1}+b_{1} \neq 0 \\
I V . & c_{0}+d_{0}=0, & a_{1}-b_{1} \neq 0
\end{array}
$$


Theorem 3. [11] We can always equivalently reduce the solution of problem (9) - (11) in the case of regular but not strongly regular conditions to a sequential of solving two problems with strongly regular Sturm boundary conditions.

We understand a generalized solution of problem (9) - (11) as a pair of functions $u(x, t) \in W_{2}^{2,1}(\Omega)$ and $f(x) \in L_{2}(0,1)$ that turn the problem into the identity almost everywhere.

The following theorem is the main result of this paper.

Theorem 4. Consider regular but not strongly regular boundary conditions (17); therefore, their coefficients satisfy one of the conditions in (18). If $\varphi(x), \psi(x) \in W_{2}^{2}(0,1)$ and satisfy the boundary conditions (12) then there exists a unique generalized solution $u(x, t) \in W_{2}^{2,1}(\Omega), f(x) \in L_{2}(0,1)$ of problem $(9)-(11)$.

Proof. Using Theorem's 1, 3, we can obtain the existence of a solution of (9) - (11), as well as its uniqueness and smoothness, for the corresponding problems with strongly regular Sturm-type boundary conditions. The presence of inhomogeneous boundary conditions on the left boundary of the domain is not a substantial obstacle and can be bypassed in a standard way.

Note that we solve problem (9) - (11) using this method independently whether the corresponding spectral problem for the operator of multiple differentiation with boundary conditions (12) enjoys the basis property for generalized eigenfunctions or not.

\section{Solution of a Mathematical Inverse Problem (6) - (8)}

To solve the inverse problem (6) - (8), we use the method developed by the authors in $[10,11]$. According to this method, the solution of problem $(6)-(8)$ is equivalently reduced to a sequential solution of two inverse problems for a diffusion equation with the other boundary conditions. These conditions are already self-adjoint boundary conditions of the Sturm-type. Therefore it is possible to use the Fourier method of variables separation for each of these two problems.

It is necessary to note that in [12] the other method of solution is used. However, due to the fact that the unknown function $f(x)$ is included not only in equation (6) but in the initial and final conditions (8), the usage of the method [12] proves impossible.

Denote the norm of the space $L_{2}(\Omega)$ by $\|u(x, t)\|_{0}$. Let the symbol $W_{2}^{2,1}(\Omega)$ stand for the space of functions $u(x, t)$ for which generalized derivatives $u_{x x}(x, t)$ exist almost everywhere, $u_{t}(x, t) \in L_{2}(\Omega)$ and

$$
\|u(x, t)\|_{2,1}^{2}=\|u(x, t)\|_{0}^{2}+\left\|u_{x x}(x, t)\right\|_{0}^{2}+\left\|u_{t}(x, t)\right\|_{0}^{2}
$$

We understand a generalized solution to problem (6) - (8) as a pair of functions $u(x, t) \in W_{2}^{2,1}(\Omega)$ and $f(x) \in L_{2}(0,1)$ that turn the problem into the identity almost everywhere. The main results of this paper are the following theorems:

Theorem 5. If functions $\varphi(x)$ and $\psi(x)$ belong to $W_{2}^{2}(0,1)$ and satisfy the conditions

$$
\varphi(1)=\psi(1)=0, \quad \varphi^{\prime}(0)-\varphi^{\prime}(1)+\alpha \varphi(0)=\psi^{\prime}(0)-\psi^{\prime}(1)+\alpha \psi(0),
$$


then problem (6) - (8) has a unique generalized solution

$$
u(x, t) \in W_{2}^{2,1}(\Omega), f(x) \in L_{2}(0,1) .
$$

From this theorem taking into account (5), we obtain the main result for the inverse problem (1) - (4):

Theorem 6. If functions $\varphi(x)$ and $\psi(x)$ belong to $W_{2}^{2}(0,1)$ and satisfy (19), then problem (1) - (4) has a unique generalized solution

$$
\Psi(x, t) \in W_{2}^{2,1}(\Omega), \quad f(x) \in L_{2}(0,1) .
$$

\section{Conclusion}

In this work, we have considered a family of problems simulating the determination of target components and density of sources from given values of the initial and final states. This model describes the process of extracting of the target component of polydisperse porous materials. The mathematical statement of these problems leads to the inverse problem for the diffusion equation, where it is required to find not only a solution of the problem, but also its right-hand side that depends only on a spatial variable.

The present inverse problem has two specificities. Firstly, the system of eigenfunctions of the multiple differentiation operator subject to boundary conditions of the initial problem does not have the basis property. Secondly, the unknown right-hand side is included both in the equation and in the conditions of initial and final redefinitions.

We have proved the unique existence of the generalized solution to the mentioned problem.

Acknowledgements. The authors express their gratitude to Prof. Tynysbek Kal'menov and Prof. Makhmud Sadybekov for valuable advices during the work.

Research supported by the grants 0820/GF4 and 0824/GF4 of the Ministry of Education and Science of Republic of Kazakhstan.

\section{References}

1. Sabitov K.B., Martem'yanova N.V. An Inverse Problem for an Equation of Elliptic-Hyperbolic Type with a Nonlocal Boundary Condition. Siberian Mathematical Journal, 2012, vol. 53, no. 3, pp. 507-519. DOI: 10.1134/S0037446612020310

2. Kirane M., Malik S.A. Determination of an Unknown Source Term and the Temperature Distribution for the Linear Heat Equation Involving Fractional Derivative in Time. Applied Mathematics and Computation, 2011, vol. 218, no. 1, pp. 163-170. DOI: $10.1016 /$ j.amc.2011.05.084

3. Kozhanov A.I. Parabolic Equations with an Unknown Absorption Coefficient. Doklady Mathematics, 2006, vol. 74, no. 1, pp. 573-576. DOI: 10.1134/S1064562406040272

4. Kostin A.B. Counterexamples in Inverse Problems for Parabolic, Elliptic, and Hyperbolic Equations. Computational Mathematics and Mathematical Physics, 2014, vol. 54, no. 5, pp. 797-810. DOI: $10.1134 /$ S0965542514020092

5. Ashyralyev A., Sarsenbi A. Well-Posedness of a Parabolic Equation with Nonlocal Boundary Condition. Boundary Value Problems, 2015, vol. 2015: 32, 11 p. DOI: $10.1186 / \mathrm{s} 13661-015-0297-5$ 
6. Ashyralyev A., Hanalyev A. Well-Posedness of Nonlocal Parabolic Differential Problems with Dependent Operators. The Scientific World Journal, 2014, vol. 2014, no. 519814. DOI: $10.1155 / 2014 / 519814$

7. Ashyralyev A., Sharifov Y.A. Counterexamples in Inverse Problems for Parabolic, Elliptic, and Hyperbolic Equations. Advances in Difference Equations, 2013, vol. 2013, no. 173, pp. $797-810$.

8. Kal'menov T.Sh., Tokmagambetov N.E. On a Nonlocal Boundary Value Problem for the Multidimensional Heat Equation in a Noncylindrical Domain. Siberian Mathematical Journal, 2013, vol. 54, no. 6, pp. 1023-1028. DOI: 10.1134/S0037446613060086

9. Kalmenov T.Sh., Shaldanbaev A.S. On a Criterion of Solvability of the Inverse Problem of Heat Conduction. Journal of Inverse and Ill-Posed Problems, 2010, vol. 18, no. 5, pp. 471-492. DOI: $10.1515 /$ jiip. 2010.022

10. Orazov I., Sadybekov M.A. One Nonlocal Problem of Determination of the Temperature and Density of Heat Sources. Russian Mathematics, 2012, vol. 56, no. 2, pp. 60-64. DOI: $10.3103 /$ S1066369X12020089

11. Orazov I., Sadybekov M.A. On a Class of Problems of Determining the Temperature and Density of Heat Sources Given Initial and Final Temperature. Siberian Mathematical Journal, 2012, vol. 53, no. 1, pp. 146-151. DOI: 10.1134/S0037446612010120

12. Orazov I., Makhatova A. An Inverse Problem of Mathematical Modeling of the Extraction Process of Polydisperse Porous Materials. AIP Conference Proceedings, 2014, vol. 1611, pp. 225-230. DOI: $10.1063 / 1.4893837$

13. Orazov I., Sadybekov M.A. One-Dimensional Diffusion Problem with Not Strengthened Regular Boundary Conditions. AIP Conference Proceedings, 2015, vol. 1690, pp. 040007. DOI: $10.1063 / 1.4936714$

14. Pyatkov S.G., Shergin S.N. On Some Mathematical Models of Filtration Theory. Bulletin of the South Ural State University. Series: Mathematical Modelling, Programming and Computer Software, 2015, vol. 8, no. 2, pp. 105-116.

15. Pyatkov S.G., Safonov E.I. Some Inverse Problems for Convection-Diffusion Equations. Bulletin of the South Ural State University. Series: Mathematical Modelling, Programming and Computer Software, 2014, vol. 7, no. 4, pp. 36-50.

16. Pyatkov S.G., Borichevskaya A.G. Some Inverse Problems for Mathematical Models of Heat and Mass Transfer. Bulletin of the South Ural State University. Series: Mathematical Modelling, Programming and Computer Software, 2013, vol. 6, no. 4, pp. 63-72. (in Russian)

17. Mihailov V.P. On Riesz Bases in $L_{2}(0,1)$. Doklady Akademii Nauk SSSR, 1962, vol. 144, no. 5, pp. 981-984. (in Russian)

18. Kesel'man G.M. On the Unconditional Convergence of Eigenfunction Expansions of Certain Differential Operators Izvestiya VUZ. Matematika, 1964, no. 2, pp. 82-93. (in Russian)

19. Dunford N., Schwartz J.T. Linear Operators, Part III. New York, John Wiley \& Sons, 1971.

Received February 28, 2016

Вестник ЮУрГУ. Серия «Математическое моделирование

и программирование» (Вестник ЮУрГУ ММП). 2016. Т. 9, № 2. С. 5-15 


\title{
ОБ ОДНОЙ МАТЕМАТИЧЕСКОЙ МОДЕЛИ ПРОЦЕССА ЭКСТРАКЦИИ ИЗ ПОРИСТОГО ПОЛИДИСПЕРСНОГО МАТЕРИАЛА
}

\author{
Н.Е. Ержанов, И. Оразов
}

\begin{abstract}
Рассматривается математическая модель, моделирующая процесс экстракции целевого компонента из пористого полидисперсного материала. Предлагаемая модель демонстрируется на примере плоского твердого материала с бидисперсными порами разного размера, в виде системы каналов макропор, на стенки которых выходят микропоры. Макропоры и микропоры в материале имеют однородный размер. Моделируется случай, когда микропоры твердого материала (дисперсионной среды) первоначально заполнены маслом (дисперсная фаза), являющимся нашей целевой компонентой. А макропоры заполнены чистым растворителем. В процессе экстракции масло диффундирует из микропоры в макропору, а затем из макропоры - во внешний объем растворителя, при этом соотношение концентраций в макропоре и микропоре принимается подчиненным линейному закону адсорбции. Обоснована корректность сформулированной математической модели.
\end{abstract}

Ключевые слова: процесс экстракции; полидисперсные пористые материалы; целевая компонента; плотность источника; обратная задача; уравнение диффузии.

\section{Литература}

1. Сабитов, К.Б. Обратная задача для уравнения эллиптико-гиперболического типа с нелокальным граничным условием / К.Б. Сабитов, Н.В. Мартемьянова // Сибирский математический журнал. - 2012. - Т. 53, № 3. - С. 633-647.

2. Kirane, M. Determination of an Unknown Source Term and the Temperature Distribution for the Linear Heat Equation Involving Fractional Derivative in Time / M. Kirane, S.A. Malik // Applied Mathematics and Computation. - 2011. - V. 218, № 1. - P. 163-170.

3. Кожанов, А.И. Параболические уравнения с неизвестным коэффициентом поглощения / А.И. Кожанов // Доклады РАН. - 2006. - Т. 409, № 6. - С. 740-743.

4. Костин, А.Б. Контрпримеры в обратных задачах для параболических, эллиптических и гиперболических уравнений / А.Б. Костин // Журнал вычислительной математики и математической физики. - 2014. - Т. 54, № 5. - С. 779-792.

5. Ashyralyev, A. Well-Posedness of a Parabolic Equation with Nonlocal Boundary Condition / A. Ashyralyev, A. Sarsenbi // Boundary Value Problems. - 2015. - V. 2015: 38 . - 11 p.

6. Ashyralyev, A. Well-Posedness of Nonlocal Parabolic Differential Problems with Dependent Operators / A. Ashyralyev, A. Sarsenbi // The Scientific World Journal. - 2014. - V. 2014, № 519814 .

7. Ashyralyev, A. Counterexamples in Inverse Problems for Parabolic, Elliptic, and Hyperbolic Equations / A. Ashyralyev, Y.A. Sharifov // Advances in Difference Equations. - 2013. V. 2013, № 173. - P. 797-810.

8. Кальменов, Т.Ш. Об одной нелокальной краевой задаче для многомерного уравнения теплопроводности в нецилиндрической области / Т.Ш. Кальменов, Н.Е. Токмагамбетов // Сибирский математический журнал. - 2013. - Т. 54, № 6. - С. 1287-1293. 
9. Kalmenov, T.Sh. On a Criterion of Solvability of the Inverse Problem of Heat Conduction / T.Sh. Kalmenov, A.S. Shaldanbaev // Journal of Inverse and Ill-Posed Problems. - 2010. V. 18, № 5. - P. 471-492.

10. Оразов, И. Об одной нелокальной задаче определения температуры и плотности источников тепла / И. Оразов, М.А. Садыбеков // Известия высших учебных заведений. Математика. - 2012. - № 2. - С. 70-75.

11. Оразов, И. Об одном классе задач определения температуры и плотности источников тепла по начальной и конечной температурам / И. Оразов, М.А. Садыбеков // Сибирский математический журнал. - 2012. - Т. 53, № 1. - С. 180-186.

12. Orazov, I. An Inverse Problem of Mathematical Modeling of the Extraction Process of Polydisperse Porous Materials / I. Orazov, A. Makhatova // AIP Conference Proceedings. 2014. - V. 1611. - P. 225-230.

13. Orazov, I. One-Dimensional Diffusion Problem with Not Strengthened Regular Boundary Conditions / I. Orazov, M.A. Sadybekov // AIP Conference Proceedings. - 2015. - V. 1690. P. 040007.

14. Pyatkov S.G., Shergin S.N. On Some Mathematical Models of Filtration Theory / S.G. Pyatkov, S.N. Shergin // Вестник ЮУрГУ. Серия: Математическое моделирование и программирование. - 2015. - Т. 8, № 2. - С. 105-116.

15. Pyatkov, S.G. Some Inverse Problems for Convection-Diffusion Equations. / S.G. Pyatkov, E.I. Safonov // Вестник ЮУрГУ. Серия: Математическое моделирование и программирование. - 2014. - Т. 7, № 4. - С. 36-50.

16. Пятков, С.Г. О некоторых обратных задачах для математических моделей тепломассопереноса / С.Г. Пятков, А.Г. Боричевская // Вестник ЮУрГУ. Серия: Математическое моделирование и программирование. - 2013. - Т. 6, № 4. - С. 63-72.

17. Михайлов, В.П. О базисах Рисса в $L_{2}(0,1)$ / В.П. Михайлов // Доклады АН СССР. 1962. - Т. 144 , № 5. - С. 981-984.

18. Кесельман, Г.М. О безусловной сходимости разложений по собственным функциям некоторых дифференциальных операторов / Г.М. Кесельман // Известия вузов СССР. Математика. - 1964. - № 2. - С. 82-93.

19. Dunford, N. Linear Operators. Part III / N. Dunford, J.T. Schwartz. - N.Y.: John Wiley \& Sons, 1971.

Нуржан Ермешевич Ержанов, кандидат физико-математических наук, доцент, ведущий научный сотрудник, Институт математики и математического моделирования (г. Алматы, Республика Казахстан), imanbaevnur@mail.ru.

Исабек Оразов, кандидат физико-математических наук, профессор, ведущий научный сотрудник, Институт математики и математического моделирования (г. Алматы, Республика Казахстан), i_orazov@mail.ru.

Поступила в редакцию 28 февраля 2016 г. 